\title{
26356 - COMPARSION OF KETAMINE-ALFENTANIL AND KETAMINE- MIDAZOLAM ON STABILITY OF BLOOD PRESSURE AND HEART RATE DURING INDUCTION OF ANESTHESIA
}

\section{Faranak Rokhabnak Assistant Professor Of Anesthesiology, Ali-reza Kholdebarin, Parviz Chabok, Iran University Of Medical Sciences, Tehra, TEHRAN, Iran}

Need to control of unwished side effects of ketamine has been evaluated in many ways. In previous investigations there has been taken some measures to diminish mean arterial pressure (MAP) and heart rate (HR) changes due to ketamine. In this consideration we compare two drugs which have been evaluated yet, but the differences: 1-There was no comparison between these two contemporary and, 2- there was many factors that interfere the study such as tracheal intubation and volatiles and so on.

This semi-clinical trial was conducted to investigate MAP and HR changes due to ketamine with alfentanil or midazolam premedication.

All patients were listed for elective surgery and were 15-45 years old and ASA-1. There were 90 patients that were arranged in three equal groups. After admitting in operating room and receiving $500 \mathrm{ml}$ of ringer lactate, MAP and HR were recorded in special forms (time-A). In group A patients have received $5 \mathrm{ml}$ of normal saline and 90 seconds later, MAP and HR were recorded (Time- B). At this time patients received iv ketamine 1 $\mathrm{mg} / \mathrm{kg}$. Thereafter MAP and HR were recorded at first (time-C), third (time-D) and fifth min (time-E) after injection of ketamine. Among these times only 100\% O2 with mask were given without any noxious stimuli. In group B alfentanil $30 \mathrm{mcg} / \mathrm{kg}$ and in group C midazolam $0.1 \mathrm{mg} / \mathrm{kg}$ instead of normal saline were received. All the other conditions were similar.

As we have three groups and the study is clinical trial, we used statistical methods (ANOVA, Post Hoc tests and Tukey). After collecting data, we conclude that both alfentanil and midazolam can successfully prevent increase of MAP and HR, due to ketamine, and no one is superior than other, so the selection of each of them depends on clinical condition of the patients. 